\title{
Nanostructured materials for solar hydrogen production
}

\author{
Joop SCHOONMAN ${ }^{\mathrm{a} *}$ and Dana PERNIU ${ }^{\mathrm{b}}$ \\ ${ }^{a}$ Delft University of Technology, Department of Chemical Engineering (ChemE), Section Materials for Energy \\ Conversion and Storage (MECS), Delft, The Netherlands \\ ${ }^{b}$ Transilvania University of Brasov, Department of Product Design, Mechatronics and Environment, 1 Colina \\ Universitatii, 500068, Brasov, Romania
}

\begin{abstract}
One of the main requirements for a future Hydrogen Economy is a clean and efficient process for producing hydrogen using renewable energy sources. Hydrogen is a promising energy carrier because of its high energy content and clean combustion. In particular, the production of hydrogen from water and solar energy, i.e., photocatalysis and photoelectrolysis, represent methods for both renewable and sustainable energy production. Here, we will present the principles of photocatalysis and the PhotoElectroChemical cell (PEC cell) for water splitting, along with functional materials. Defect chemical aspects will be high-lighted. To date, the decreasing length scale to the nanoscale of the functional materials attracts widespread attention. The nanostructure is beneficial in case diffusion lengths of the photo-generated charge carriers are substantially different.
\end{abstract}

Keywords: Hydrogen, photocatalysis, PEC cells, defect chemistry, nanosize

\section{Introduction}

An important industrial process to produce the energy carrier hydrogen is based on the hightemperature steam-reforming reaction of hydrocarbons and the subsequent water-gas shift reaction at lower temperatures to convert the formed $\mathrm{CO}$ with steam to $\mathrm{CO}_{2}$. For methane, $\mathrm{CH}_{4}$, the steam-reforming and water-gas shift reactions produce four molecules of hydrogen per methane molecule. Basically, more than $90 \%$ of the yearly worldwide production of $45 \times 10^{9} \mathrm{~kg}$ of hydrogen is being produced using fossil fuels [1].

However, one of the principle requirements for a future Hydrogen Economy is a clean, $\mathrm{CO}_{2}$-free, sustainable and efficient route for the production of hydrogen, using, for instance, wind and solar energy. In particular, the production of hydrogen by splitting water using solar energy can be achieved via photocatalysis and photoelectrolysis.

Many research efforts on solar water splitting are directed towards systems based on a photocatalyst nanosized powder suspended in an aqueous solution. Incident light penetrates the suspension and generates electron-hole pairs in the photocatalytic particles and subsequently the electrons and the electron holes will reduce and oxidize water at different surface sites of the particles [2-5].

Fujishima and Tryk [6] published the first report in English on photochemical and photoelectrochemical water splitting, followed by the landmark paper of Fujishima and Honda [7] presenting a PhotoElectroChemical cell (PEC cell), based on a n-type rutile-structured $\mathrm{TiO}_{2}$ photoanode. While indeed water splitting can be carried out with coupled solar cells-water electrolyzers, the direct photoelectrolysis is a more elegant and cheaper approach [8,9]. Here, the photoactive semiconductor is immersed in water and the photogenerated electrons and holes are directly used to reduce and oxidize water, respectively. The direct photoelectrolysis is the Holy Grail of electrochemistry, using the power of light. The average energy of an electron is $0.025 \mathrm{eV}$ at room temperature and, for instance, one green photon has 
an energy of $2.5 \mathrm{eV}$ at room temperature. An important advantage of the PEC cell is that evolving hydrogen and oxygen gases can be collected in separate volumes.

Here, we will focus on photocatalytic materials in suspension and photoelectrode materials for the PEC cell. Examples of the role of doping, engineering on an atomic scale, will be discussed.

Irradiation of a dispersion of a photocatalyst powder in water is an important route to solar hydrogen. Van de Krol et al. [10] have presented recently an overview of particle-based photocatalyst systems that are able to split water in stoichiometric ratios. Fig. 1 shows schematically the photocatalytic water splitting under irradiation. The oxidation and reduction reactions take place at the same surface of a single particle and in order to avoid recombination of oxygen and hydrogen and electrons and holes usually small amounts of co-catalysts with nanodimension are deposited on the surface of the photocatalyst, i.e., $\mathrm{Pt}, \mathrm{NiO}, \mathrm{NiO}_{\mathrm{x}}$, or $\mathrm{RuO}_{2}$, in order to ensure that oxygen and hydrogen evolve at spatially separate surface sites.

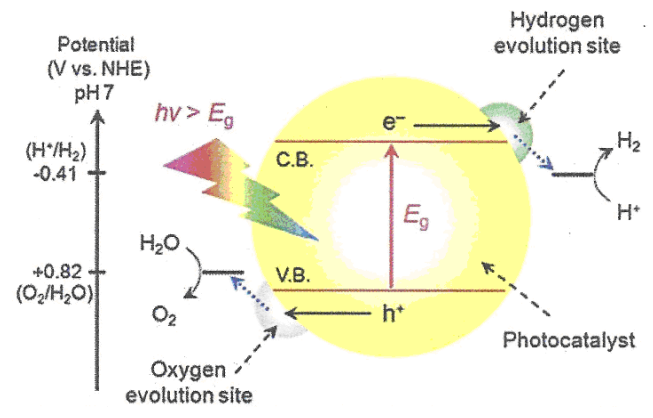

Fig. 1. Energy diagram for a particle-based photocatalyst and the water splitting reactions [2].

Many photocatalysts are only able to evolve either oxygen or hydrogen and not lead to the stoichiometric splitting of water. If only oxygen (hydrogen) evolves, a sacrificial electron acceptor (electron donor) needs to be present to ensure the stoichiometric splitting of water in $\mathrm{a}_{2}: \mathrm{O}_{2}$ ratio of 2:1.

The photocatalyst can be an ionic nonsemiconducting material (stoichiometric $\mathrm{TiO}_{2}$, $\mathrm{ZrO}_{2}$ ), or a semiconductor (n-CdS, n- $\mathrm{Ga}_{2} \mathrm{O}_{3}$ ). In addition to binary materials, ternary and more complex materials are being studied recently. Examples are I-III- $\mathrm{VI}_{2}$ ternary semiconductors with chalcopyrite structure such as $\mathrm{AgInS}_{2}$ and $\mathrm{CuInS}_{2}$ [11].

In mixtures of photocatalytic particle systems the oxidation and reduction of water take place on two different particles which not need to be in direct contact with each other. Overall water splitting through a two-step photoexcitation (Z-scheme) was reported by Maeda et al. [12]. For the Z-scheme a $\mathrm{RuO}_{2}-\mathrm{TaON}$ photocatalyst was used in combination with a Pt-loaded $\mathrm{ZrO}_{2}$-TaON photocatalyst for hydrogen evolution from an aqueous $\mathrm{NaI}$ solution. The Z-scheme is presented in Fig. 2.

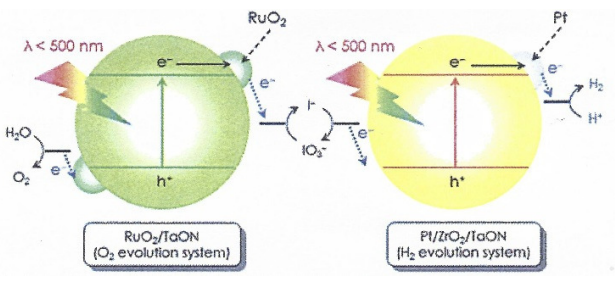

Fig. 2. The overall water splitting through two-step photoexcitation of an $\mathrm{O}_{2}$ evolution photocatalyst and a $\mathrm{H}_{2}$ evolution photocatalyst [12].

Madea et al. [13] have reported recent research progress in the development of visible-light-driven photocatalysts, focusing on the refinement of nonoxide type photocatalysts, such as (oxy)nitrides and oxysulfides. These materials absorb visible light in the spectral range $450-700 \mathrm{~nm}$ and are stable photocatalysts for the oxidation and reduction of water. Novel non- $\mathrm{TiO}_{2}$ photocatalysts have recently been reviewed by Jin Chao et al. [14]. These include $\mathrm{Ag}_{3} \mathrm{PO}_{4}$-based composites, non- $\mathrm{TiO}_{2}$ metal oxides, sulfides, bismuth compounds, and cobalt compounds.

The field of heterogeneous photocatalysis has undergone various evolutionary phases related not only to energy but also to environment and while indeed the most significant environmental photocatalysis is the solar water splitting, the purification of air and water, including self cleaning surfaces are being studied world wide [15]. The interdisciplinary nature of the field has recently been presented by Teoh et al. [4]. 


\section{PhotoElectroChemical Cells}

The operating principle of a PEC cell, comprising an n-type semiconductor photoelectrode and an inert metallic counter electrode immersed in an aqueous solution, is based on the formation of a Schottky barrier at the interface semiconductoraqueous electrolyte. Electrons from the n-type semiconductor will occupy surface states at the interface in order to compensate for the difference in the electrochemical potential of both phases and a space charge results in the semiconductor. If the semiconducting photoelectrode is now irradiated with photons that have an energy equal or beyond the bandgap energy of the semiconductor, electrons are photoexcited from the valence band of the semiconductor into its conduction band. Under the influence of the space charge field the photoelectrons travel to the back contact and are transported via the electrical circuit to the counter electrode, where they reduce water to form hydrogen. The photoelectron holes in the valence band diffuse in the space charge field to the interface photoelectrode-electrolyte, where they oxidize water to form oxygen. The chemical reactions are written for an alkaline solution. The space charge field prevents the recombination of the photoexcited charge carriers. Fig.3 presents the principle of operation of the PEC cell.

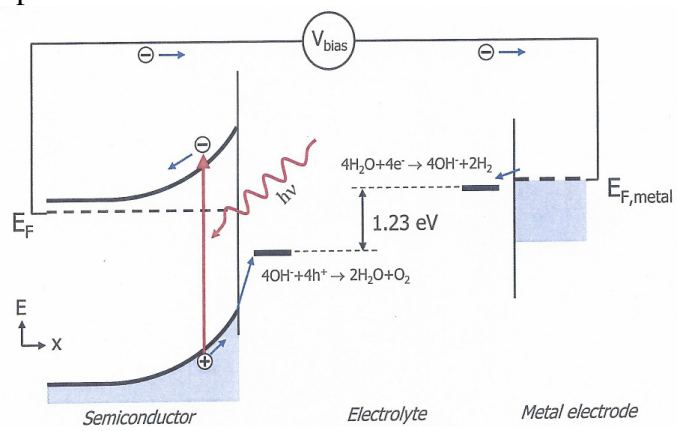

Fig. 3. Schematic energy diagram of a PEC cell with an n-type photoanode for the splitting of water in oxygen and hydrogen $[9,16]$.

The schematic energy band diagram holds for the PEC cell under irradiation. Compared to the energy band diagram of the PEC cell in equilibrium in the dark, irradiation decreases the band bending and near the semiconductor-electrolyte interface the Fermi level $\mathrm{E}_{\mathrm{F}}$ splits into quasi-Fermi levels for electrons and electron holes [17]. In Fig. 3 only the quasi-Fermi level of the electrons is included. A bias potential will be required to aid the reduction reaction if the conduction band edge is positioned below the reduction potential of water.

The selection of the semiconductor electrode is of paramount importance. Suitable materials should exhibit strong visible-light absorption, have a high chemical stability in the dark and under illumination, valence $\left(E_{v}\right)$ and conduction $\left(E_{c}\right)$ band edge positions that enable oxidation and reduction of water (see Fig. 3), efficient transport of the photogenerated charge carriers in the semiconductor, low overpotentials for the electrode reactions, and low cost. The bandgap of the photoelectrode material determines the spectral region in which the semiconductor absorbs light. The minimum bandgap is determined by the theoretical energy to split water $(1.23 \mathrm{eV})$, plus the thermodynamic losses of about $0.4 \mathrm{eV}$ [17], and the overpotentials $(\sim 0.3-0.4 \mathrm{eV})$ to ensure fast electrode reaction kinetics [18,19]. Hence, the bandgap energy should be at least $2,0 \mathrm{eV}$, but the most optimal value of the bandgap energy is determined by the solar spectrum.

The optimal bandgap energy $\left(E_{g}\right)$ for photoelectrolysis can be calculated using Eq. (1).

$$
\mathrm{E}_{\mathrm{g}}=\mathrm{hc} / \lambda
$$

Here, h is Planck constant $\left(4.136 \times 10^{-15} \mathrm{eV} / \mathrm{s}\right)$, c the speed of light $\left(3 \times 10^{8} \mathrm{~m} / \mathrm{s}\right)$ and hence Eq. (1) reads,

$$
\mathrm{E}_{\mathrm{g}}(\text { in } \mathrm{eV})=1240 / \lambda(\mathrm{nm})
$$

According to Murphy et al. [19] the ideal material has a bandgap energy of $2.03 \mathrm{eV}, \lambda_{\text {onset }}$ of $610 \mathrm{~nm}$, and a maximal theoretical conversion efficiency of $16.8 \%$ at AM1.5. Hematite, $\alpha-\mathrm{Fe}_{2} \mathrm{O}_{3}$, approaches the ideal material with a bandgap energy of $2.10 \mathrm{eV}$, $\lambda_{\text {onset }} 590 \mathrm{~nm}$, and $12.9 \%$ as estimated maximal conversion efficiency. Other state-of-the-art semiconductors. like $\mathrm{CdS}, \mathrm{GaP}, \mathrm{WO}_{3}, \mathrm{TiO}_{2}$ (rutile), $\mathrm{TiO}_{2}$ (anatase), and $\mathrm{ZnO}$ have bandgap energies ranging from 2.25 to $3.37 \mathrm{eV}$ with decreasing efficiences down to $1.3 \%$ for anatase $\mathrm{TiO}_{2}$.

The ionic semiconducting metal oxides usually exhibit an indirect transition which means that the 
absorption of a photon is accompanied by the absorption or emission of a phonon, which is not an efficient process. In addition, the diffusion pathway of the minority carriers is usually limited, for instance, the photoexcited electron holes in $\mathrm{WO}_{3}$ and $\alpha-\mathrm{Fe}_{2} \mathrm{O}_{3}$ recombine within 150 to $20 \mathrm{~nm}$, respectively $[1,16]$. These short diffusion pathways are due to the presence of lattice defects, which can act as recombination centers. While improved thinfilm synthesis techniques may lead to reduced concentrations of lattice defects, a more advanced approach is the development of nanostructured surface morphologies, in order to reduce the diffusion pathways of photogenearated charge carriers. Several nanostructured surface morphologies have been reported. The deposition of fractal shaped $\mathrm{TiO}_{2}$ photoanodes by Chemical Vapor (CVD) deposition has been reported [20,21].

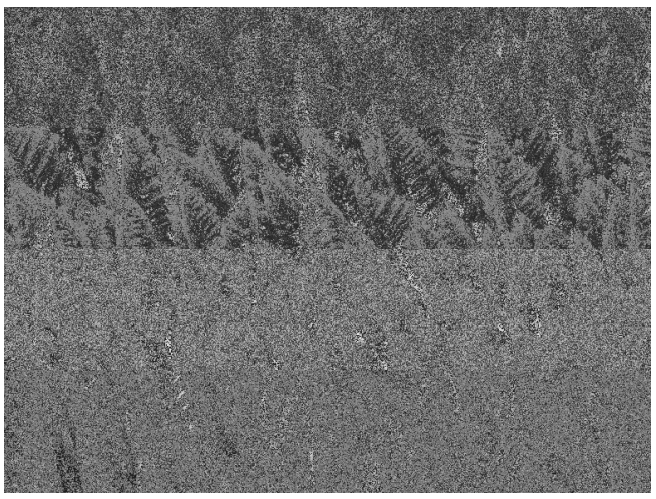

Fig. 4. Scanning electron micrograph of fractalshaped $\mathrm{TiO}_{2}$, co-doped with $\mathrm{Cr}$ and Fe, as deposited by CVD.

This surface morphology enhances the absorption through extensive light scattering, while the high aspect ratio ensures that the optically excited electron holes have to travel only short distances to the interface with the electrolyte.

This fractal shaped co-doped $\mathrm{TiO}_{2}$ exhibited a substantial increase in photocurrents under visiblelight excitation, compared to dense undped and dense $\mathrm{Cr}$ and $\mathrm{Fe}$ co-doped $\mathrm{TiO}_{2}$, ascribed to this nano-structured surface morphology [21]. Low- and high-temperature oxididation of Fe foil in air leads to nanostructured morphologies with different aspect ratios [10]. An example is presented in Fig. 5.

This surface morphology especially solves the electron hole diffusion pathway in hematite.

\section{Defect Chemistry}

Wide-bandgap metal oxide semiconductors, like $\mathrm{TiO}_{2}$, usually absorb the near UV and many research efforts have been focused on shifting the optical absorption towards the visible part of the solar spectrum. Hereto, doping with aliovalent cations and anions has been studied in detail. With regard to cation doping, the main focus has been on $3 \mathrm{~d}$ transition metal ions, like $\mathrm{Cr}$ and $\mathrm{Fe}$. In $\mathrm{TiO}_{2}$, these dopant ions occupy Ti-sites and introduce localized defect energy levels in the bandgap.

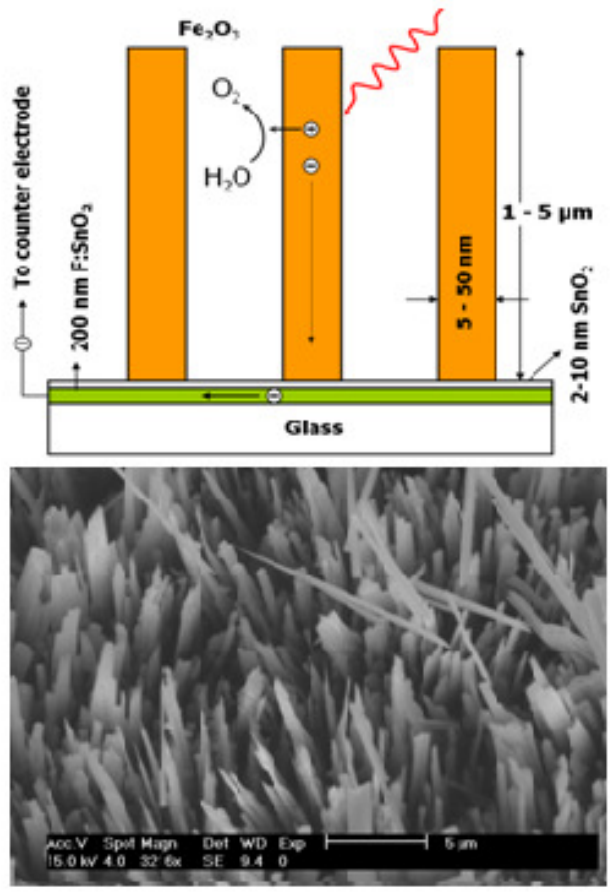

Fig. 5. Thermal oxidation of Fe foil at $800{ }^{\circ} \mathrm{C}$ in an air flow of $25 \mathrm{sccm}$.

Besides, they have an effective negative charge, i.e. $\mathrm{Cr}^{3+}$ on a $\mathrm{Ti}^{4+}$, which in the Kröger-Vink defect chemical notation would be represented by $\mathrm{Cr}_{\mathrm{Ti}}$ ', where the symbol 'denotes an effective charge $-\mathrm{q}$. 
The symbol denotes an effective charge $+\mathrm{q}$, like $\mathrm{Ta}^{5+}$ on a $\mathrm{Ti}^{4+}$, i.e. $\mathrm{Ta}_{\mathrm{Ti}}{ }^{\cdot}$ [22]. While excitation of electrons from these localized defect energy levels is achieved with visible light, the photoelectron holes need to hop from one energy level to another, which is a much slower process than the mobility of the photoelectron holes in the valence band. These types of localized defect energy levels increase the chance for charge trapping and recombination and the cation-doping route does not improve the overall efficiency of photoelectrodes.

Asahi et al. reported on anion doping of $\mathrm{TiO}_{2}$ [23]. Their quantum chemical calculations revealed that the wave functions of anion dopants $\mathrm{N}$ and $\mathrm{C}$ show significant overlap with the oxygen valence band wave functions, which means that the subbandgap defect energy levels are less localized than for the cation dopants. This would reduce recombination substantially and $\mathrm{N}$ and $\mathrm{C}$ doping of $\mathrm{TiO}_{2}$ has indeed been shown to improve photocatalytic activities [24,25].

The deposition of $\mathrm{N}$ - or C-doped thin-film $\mathrm{TiO}_{2}$ photoanodes using spray pyrolysis under a $\mathrm{CO}_{2}$ atmosphere [26], or a high-temperature treatment of a film in a hexane-containing ambient [27] revealed too low dopant concentrations for a significant change in the absorption spectrum.

Several routes have been studied to increase the concentration of the anion dopants $\mathrm{N}$ and $\mathrm{C}$. The oxidative annealing of TiN films has been proposed to be a promising route [28]. Xinguo $\mathrm{Ma}$ et al. have studied compensated and noncompensated co-doped anatase $\mathrm{TiO}_{2}$ with the anion dopant $\mathrm{N}$ or $\mathrm{C}$ and the transition metal $\mathrm{Nb}$ or $\mathrm{Ta}$. It is found that especially for the 1:2 charge compensated co-doped $\mathrm{Nb}-\mathrm{C}-\mathrm{Nb}$ and Ta-C-Ta systems the energy gap becomes smaller thus enhancing the optical absorption. Their calculations reveal that co-doping with transition metals facilitates an enhancement of the concentrations of the $\mathrm{N}$ and $\mathrm{C}$ dopants. The dopants $\mathrm{N}$ and $\mathrm{C}$ will have an effective negative charge $-2 \mathrm{q}$, i.e., $\mathrm{N}_{\mathrm{O}}$ " and $\mathrm{C}_{\mathrm{O}}$ ", which can be charge compensated by two $\mathrm{Nb}$ or $\mathrm{Ta}$ dopants, i.e., $\mathrm{Nb}_{\mathrm{Ti}}{ }^{\circ}$ and $\mathrm{Ta}_{\mathrm{Ti}}{ }^{\cdot}$. With charge compensated co-doping local trapping of optically excited charge carriers is eliminated improving charge carrier mobility and conversion efficiency.

Besides doping, a deviation from stoichiometry will influence the lattice defect concentrations. This deviation is presented in the defect chemical lattice reaction,

$$
\mathrm{O}_{\mathrm{O}}{ }^{\mathrm{x}} \leftrightarrow \mathrm{V}_{\mathrm{O}}{ }^{\prime \prime}+1 / 2 \mathrm{O}_{2}+2 \mathrm{e}^{\prime}
$$

An oxide ion with an effective charge 0q, symbol $\mathrm{O}_{\mathrm{O}}{ }^{\mathrm{x}}$, leaves the lattice as oxygen, thereby creating an oxide ion vacancy with an effective charge +2q, symbol $\mathrm{V}_{\mathrm{O}}{ }^{\prime}$, which is charge compensated by two electrons having an effective charge -q, symbol e'. Here, both ionic and electronic disorder is influenced. To obtain in depth information of the influence of a deviation from stoichiometry a Brouwer diagram is constructed: $\log$ [defect concentration] versus $\log p\left(\mathrm{O}_{2}\right)^{1 / 2}$ and reveals which ionic and electronic defects dominate in a certain $p\left(\mathrm{O}_{2}\right)$ regime. In the case of binary materials only deviations from stoichiometry occur, which influence ionic and electronic disorder.

The defect chemistry of I-III- $\mathrm{VI}_{2}$ chalcopyritestructured materials with $\mathrm{CuInS}_{2}$, as example, has been reported by Perniu et al. [29-31]. In ternary and more complex materials deviations from stoichiometry and molecularity can occur.

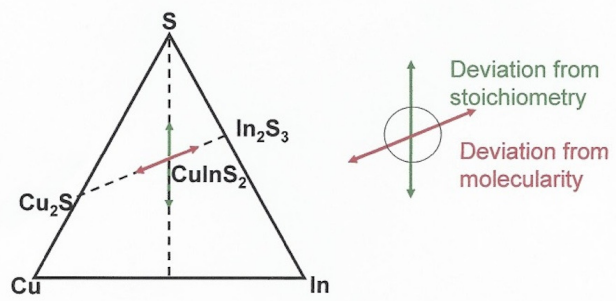

Fig. 6. Schematics of deviations from stoichiometry and molecularity in $\mathrm{CuInS}_{2}$.

Here, several basic defect chemical lattice reactions will be presented in order to illustrate these deviations. The deviation from stoichiometry is illustrated with the lattice reaction,

$$
1 / 2 S_{2}(g)+V_{S}^{\prime \prime} \leftrightarrow S_{S}{ }^{x}+2 h^{*}
$$

S will occupy a sulfide ion vacancy and its effective charge is compensated by the formation of two electron holes with an effective charge $+q$. 
Deviations from molecularity are for $\mathrm{Cu}$-rich and Inrich materials as follows:

$$
\mathrm{Cu}_{2} \mathrm{~S} \leftrightarrow \mathrm{Cu}_{\mathrm{Cu}}{ }^{\mathrm{x}}+\mathrm{Cu}_{\mathrm{In}}{ }^{\prime \prime}+\mathrm{S}_{\mathrm{S}}{ }^{\mathrm{x}}+\mathrm{V}_{\mathrm{S}}
$$

For the $\mathrm{Cu}$-rich material an anti-site copper ion is charge compensated with a sulfide ion vacancy.

$$
\mathrm{In}_{2} \mathrm{~S}_{3} \leftrightarrow 2 \mathrm{~V}_{\mathrm{Cu}}{ }^{\prime}+2 \operatorname{In}_{\text {In }}{ }^{\mathrm{x}}+3 \mathrm{~S}_{\mathrm{S}}{ }^{\mathrm{x}}+\mathrm{V}_{\mathrm{S}}
$$

Deviations from molecularity only influence ionic disorder.

The combinations of a deviation from stoichiometry and molecularity are exemplified in the following lattice reactions:

$$
\begin{gathered}
\mathrm{Cu}_{2} \mathrm{~S}+1 / 2 \mathrm{~S}_{2}(\mathrm{~g}) \leftrightarrow \mathrm{Cu}_{\mathrm{Cu}}{ }^{\mathrm{x}}+\mathrm{Cu}_{\mathrm{In}}{ }^{\prime \prime}+ \\
+2 \mathrm{~S}_{\mathrm{S}}{ }^{\mathrm{x}}+2 \mathrm{~h}
\end{gathered}
$$

The effective charge of the anti-site $\mathrm{Cu}$ íon is now charge compensated by two electron-holes. In the In-rich material the effective charge of the copper ion vacancies is charge compensated by two electronholes:

$$
\begin{gathered}
\operatorname{In}_{2} \mathrm{~S}_{3}+1 / 2 \mathrm{~S}_{2}(\mathrm{~g}) \leftrightarrow 2 \mathrm{~V}_{\mathrm{Cu}}{ }^{\prime}+2 \operatorname{In}_{\mathrm{In}}{ }^{\mathrm{x}}+ \\
+4 \mathrm{~S}_{\mathrm{S}}{ }^{\mathrm{x}}+2 \mathrm{~h}^{\circ}
\end{gathered}
$$

Brouwer diagrams of $\log$ [defect concentration] versus $\log p\left(\mathrm{~S}_{2}\right)$ and $\log$ [defect concentration] versus $\log$ activities of the binary metal sulfides, i.e. $\mathrm{Cu}_{2} \mathrm{~S}$ and $\operatorname{In}_{2} \mathrm{~S}_{3}$ were derived and used to construct a $3 \mathrm{D}$ Brouwer diagram. This approach can also be applied to develop the complete defect structure of other IIII- $\mathrm{VI}_{2}$ materials.

\section{Concluding remarks}

The search for optimal materials to be used as a photocatalyst or a photoelectrode for the production of the energy carrier hydrogen by splitting water under solar irradiation is a very active field of research. Modification of a photocatalyst with a cocatalyst and of a photelectrode are important physical and materials chemistry challenges with focus on composition, interfaces, nanosize, and defect chemistry. Nanostructured particle sizes and surface morphologies are beneficial if large differences in the diffusion pathways of the optically excited charge carriers exist in a material. For promising and new materials, it is important to have detailed insight into the lattice defects of the materials. This knowledge is required in order to select appropriate dopants to enhance the concentration of desired lattice defects. It is shown how cation co-doping can enhance the incorporation of anion dopants. In general, it is important for the interpretation of properties of ternary and more complex materials to take both deviations from stoichiometry and molecularity into account.

\section{References}

* E mail address: J.Schoonman@tudelft.nl

[1]. B. Dam and R. van de Krol, Netherland's Journal of Physics, June 2011, 174 (in Dutch).

[2]. K. Maeda and K. Domen, J. Phys. Chem. Letters 1, 2655 (2010).

[3]. A. Mukherji, Ch. Sun, S.C. Smith, G. Qing Lu, and L. Wang, J. Chem. Phys. C, 115, 15674 (2011).

[4]. W.Y. Teoh, J.A. Scott, and R. Amal, J. Phys. Chem. Letters 3, 629 (2012).

[5]. P.V. Kamat and J. Bisquert, J. Phys. Chem. C, 117, 14873 (2013).

[6]. A. Fujishima and D.A. Tryk, in Energy Carriers and Conversion Systems. Volume 1 (1968). Encyclopedia of Life Support Systems (EOLSS). http://www.eolss.net/ EolsssampleAllChapter.aspx.

[7]. A. Fujishima and K. Honda, Nature 238, 37 (1972).

[8]. M. Grätzel, Nature 414, 338 (2001).

[9]. R. van de Krol and J. Schoonman, Chapter 6, in Sustainable Energy Technologies: Options and Prospects. Eds. K. Hanjalić, R. van de Krol,and A. Lekić, Springer, 2008.

[10]. R. van de Krol, Y. Liang, and J. Schoonman, J. Mater. Chem. 18, 2311 (2008).

[11]. T. Torimoto, T. Kameyama, and S. Kuwabata, J. Phys. Chem. Letters 5, 336 (2014).

[12]. K. Maeda, R. Abe, and K. Domen, J. Phys. Chem. C 115, 3057 (2011).

[13]. K. Madea, T. Takata, and K. Domen, in Energy Efficiency and Renewable Energy Through Nanotechnology, Green Energy and 
Technology. Ed. L. Zang, Springer-Verlag London Limited. 2011, pp. 487-529. DOI: 10.1007/978-0-85729-638-2-14.

[14]. Jin Chao, Qin Yao, and Yang Jinhu, Progr. in Chem. 26, 225 (2014) (in Chinese).

[15]. A. Fujishima, T.N. Rao, and D.A. Tryk, J. Phys. Chem. Photobiology C: Photochemistry Reviews 1, 1 (2000).

[16]. R. van de Krol and M. Grätzel eds. Photoelectrochemical Hydrogen Production, Electronic Materials: Science and Technology 102. Springer New York, Dordrecht, Heidelberg, London, 2012. ISBN 978-1-4614-1379-0.

[17]. M.F. Weber and M.J. Dignam, Int. J. Hydrogen Energy 11, 225 (1986).

[18]. R.J. Bolton, S.J. Strickler, and J.S. Connoly, Nature 316, 495 (1985).

[19]. A.B. Murphy, P.F.R. Barnes, L.K. Randeniya, I.C. Plumb, L.E Grey, M.D. Horne, and J. Glasscock, Int. J. Hydrogen Energy 31, 1999 (2006).

[20]. A. Goossens, E.L. Maloney, and J. Schoonman, Chem. Vap. Deposition 4109 (1998).

[21]. J.C. van 't Spijker, E.L. Maloney, J. Schoonman, and R. van de Krol, $16^{\text {th }}$ International Conference on Photochemical Conversion and Storage of Solar Energy, IPS16, Uppsala, Sweden 2006.

[22]. F.A. Kröger, The Chemistry of Imperfect Crystals. North-Holland publishing Co. Amsterdam, 1964.
[23]. R. Asahi, T. Morikawa, T. Ohwaki, K. Aoki, and Y. Taga, Science 293, 269 (2001).

[24]. S. Sakthivel and H. Kisch, Angew. Chem. Int. Ed. 42, 4908 (2003).

[25]. X.B. Chen, Y.B. Lou, A.C.S. Samia, C. Burda, and J.L. Gole, Adv. Funct. Mater. 15, $41(2005$.

[26]. C.S. Enache, J. Schoonman, and R. van de Krol, J. Electrocer. 13, 177 (2004).

[27]. C.S. Enache, J. Schoonman, and R. van de Krol, Appl. Surf. Sci. 252, 6342 (2006).

[28]. H. Ieri, Y. Watanabe, and K. Hashimoto, Chem. Lett. 32, 772 (2003).

[29]. D. Perniu, M. Nanu, R. van de Krol, and J. Schoonman, in Nanostructured and Advanced Materials for Application in Sensor, Optoelectronic and Photovoltaic Technology. Book series: NATO Science series IIMathematics, Physics, and Chemistry. Vol. 204, 251 (2005).

[30]. D. Perniu, S. Vouwzee, A. Duta, and J. Schoonman, J. Optoelec. Advanced Mater. 9, 1568 (2007).

[31]. D. Perniu, A. Manciu, L. Isac, and J. Schoonman, J. Optoelec. Advanced Mater.Symposia, Vol. 6, 992 (2009).

Submitted: May $10^{\text {th }} 2014$ Accepted without revision: May $17^{\text {th }} 2014$ 